Journal of Social Sciences 4 (4): 352-357, 2008

ISSN 1549-3652

(C) 2008 Science Publications

\title{
Economic Implication of Poverty Alleviation Programs on Rural Women in Ondo-State Case Study of Country Women Association of Nigeria
}

\author{
Fasoranti Mary Modupe \\ Department of Economics, Adekunle Ajasin University, Akungba Akoko, Ondo State, Nigeria
}

\begin{abstract}
The study examined the economic implication of COWAN poverty alleviation programme in rural women. Multi-stage sampling technique was used to select 100 respondents from Ikare and Ugbe from Akoko North East and Oka and Akungba from Akoko South West. The data collected were analysed with the aid of descriptive statistics and simple regression analysis to examine the socioeconomic characteristics of respondents and the efficiency of COWAN micro finance initiative. Results showed that $35 \%$ of respondents have no formal education while 30, 24 and $11 \%$ has primary school, secondary school and above secondary education respectively. The mean age reported was 39 years showing that the respondents were still in their economically active years. Result also showed that loans facilities from COWAN has positive influence on the level of income and the result of the return to scale analysis showed efficient utilization of the loans. It is therefore recommended that COWAN should be encouraged to give greater loans facilities to interested borrowers in the study area.
\end{abstract}

Key words: Poverty alleviation, COWAN, economic implication, development.

\section{INTRODUCTION}

Poverty is a common plague afflicting people all over the world especially in the less developed countries. According to M.L. Jhingan (2003), poverty is misery-go-round plaguing the less developed countries $^{[1]}$.

Nigeria enjoyed steady economic growth and relative stability in the 1960 s and 70 s especially with emergence of the mining industries. The per-capita income grew steadily and few people were between the poverty line as the agricultural public and industrial sectors absorbed a highest percentage of the labor force.

However, as from the late 70s, the economy had to contend with severe economic difficulties resulting from falling oil revenue, world economic recession, deteriorating terms of trade, debt overhangs and macroeconomic imbalances. Other factors were high inflation rate, unemployment, bad economic principles, huge wastage of scarce resources and bad governance. Hence, poverty has remained one of the most pressing issues in Nigeria today. It has not only become entrenched and multifaceted over the years, it has defied efforts at eradicating it. Poverty is associated with lack of inadequate basic necessities of life such as food, clothing, light and shelter among others.

Prior to the 1970s, there was this general belief that rapid economic growth (i.e., increase in productivity) and rising per capita income would automatically improve people's welfare. However, experience soon proved that high economic growth would necessarily transform income structure into an equitable distribution of benefits as the country experienced high inflation and unemployment. Hence, attention was shifted to the development of human capital in line with the basic human needs approach to alleviating poverty in the 1980s consequently, Nigeria embraced greater investment in education, infrastructural development, health, nutrition and other social sector. However this approach soon ran to a hitch due to the economic crisis of the mid 80s. Consequently, the incidence of poverty rose to 43 percent in 1985, though it fell to 34\% in 1992 due to the 1986 structural reforms ${ }^{[2]}$. However, with the collapse of macro economic discipline in the 1990s, the country was plagued with high inflation, low productive activities and economic stagnation. The poverty incidence rose to $61 \%$ in 1997 and over $70 \%$ in 1999 . and Nigeria ranked $54^{\text {th }}$ in the Human Poverty Index ${ }^{[2]}$.

The situation above called for concerned efforts by all stake holders namely, the government, multinational organizations, community based institutions, private and non-governmental organization to improve the living standard of the populate. The various governments at all levels at different times embarked on poverty alleviation programs to cushion the effects of poverty. Such programs among others included the Directorate of Food, Roads and Rural Infrastructure (DFRRI), Better Life Program (BLP), Family Support Program (FSP), National Directorate of Employment (NDE), Family Economic Advancement Program 


\section{J. Social Sci., 4 (4): 352-357, 2008}

(FEAP), People's Bank of Nigeria, Federal Urban Mass Transit Program, National Agency for Mass Literacy and National Agricultural Land Development Authority (NALDA).

Despite the laudable programs outlined above and the huge scarce resources devoted to poverty alleviation, the level of unemployment especially among women and youth continued to rise while poverty conditions worsened. The past efforts were probably undermined by deteriorating in fiscal discipline, corruption, political instability, bad governance, financial indiscipline and inconsistent government policies. In recognition of the economic implication of poverty and the failure of past governmental efforts, some non-governmental organizations have stepped efforts to alleviate poverty among the women folks living in the rural areas. Worthy of note of these organizations is the Country Women Association of Nigeria (COWAN). COWAN aimed at alleviating poverty among women living in the rural areas.

Women have always seen at the vanguard of development. In a typical African setting, women are responsible for over $70 \%$ of food production and processing. Nevertheless, they have little or no access to productive assets. Most often times, she is denied access to loan facilities for lack of collateral securities. In realization that women empowerment and the improvement of their political, social, economic and health status are essential for development, it is imperative therefore to examine the impact of the micro finance provided by COWAN on poverty alleviation among rural women.

This study therefore aims at examining the activities of COWAN as it relates to poverty alleviation among rural women. The study, examines the socioeconomic characteristics of COWAN beneficiaries, the influence of micro-finance provided by COWAN on selected socio-economic variables of women and the role of COWAN in women's economic, social and political empowerment.

Literature review: Poverty has generally been defined as a state of having little or no money and the failure to get necessities of life. It is a hydra-headed condition which tends to restrict people from socio-economic opportunities. According to ${ }^{[3,4]}$ the poor is defined as one who lacks basic necessities such as adequate feeding, clothing, good health, education, supply of portable water, electricity and good road among others. However, Afolami ${ }^{[5]}$ emphasized that the poor is one who cannot boast of subsequent meals apart from what he/she has for the moment i.e. he/she is not sure of where to get the next meals. According to Fasoranti $(2007)^{[6]}$, poverty covers economic, human, political, socio-cultural and protective abilities of the society. Hence, it could be said that poverty is a multidimensional concept whose definitions varies according to gender, culture, age and other socioeconomic factors.

Many reasons have been advanced for poverty in the less developed countries. Chandhri ${ }^{[7]}$, Chambers ${ }^{[8]}$, Akinde $^{[9]}$ and Fasoranti ${ }^{[6]}$ concluded that traditional technology, unchanging farmer's experience, laziness, ignorance, stupidity, urban-biased development, exploitation of the rural population by the urban elites and personal bad luck among others are the basic causes of poverty. The devasting effects of poverty can not be over emphasized. It results into hunger, diseases, inadequate shelter and homelessness as part of the consequences of poverty. In our contemporary time, the poor man/woman has no voice in the society, lacks political influence, personal recognition; he is often emotionally and psychologically distressed and are always the downtrodden elements in the society. According to ${ }^{[10]}$, the problems of the poor include social inferiority, isolation, physical weakness, vulnerability, powerlessness and humiliation. Others such as Okunmadewa $^{[11]}$, Olowononi ${ }^{[12]}$ and Evbuomwan ${ }^{[13]}$ asserted that the poor is plagued with exposure to risk, limited opportunities to income generation, misery, crime, untimely death, fear, despondency depression and suicide.

Studies have indicated that women suffer poverty on a more widespread basis than men and that their experience of poverty is quite different as a result of expectation about their gender roles. It has been estimated that women constitute $70 \%$ of the world's 1.2 billion poor. Many factors could be responsible for the poverty among the women folks of such include the concentration of women in low-paid job, limited education, discrimination by many employers of labour, poor stake of health and male chauvinism in most Nigerian communities.

The Country Women Association of Nigeria (COWAN): The Country Women Association was born of out a passion for the improvement and empowerment of rural women. The association started at a meeting of over 100 women comprising of two women from each of the 35 Local Government Areas of the defunct Ondo State in 1982. The organization was earlier known as Rural Women Association. The vision of the organization was that of building human dignity by integrating contemporary economic practices into local tradition, knowledge and skills using our own 
human and natural resources to create wealth. It was the belief of the initiators of COWAN that sustainable poverty alleviation programs should be gender sensitive and work towards enhancing gender equality in access to resources. To accomplish thus the following objectives were outlined $^{[14]}$ :

- Harnessing and sharing information about relevant culture, knowledge and practices for poverty eradication and wealth creation

- Training, retraining and equipping women in the appropriate skill and technologies for better productivity, new ventures and self-employment

- Targeting the poorest of the poor for special services and products delivery

- Promoting women's participation in politics that is voting and being voted for

- Highlighting and celebrating the inherent strengths and value of the informal sector as the harbinger of the African economy and the cornerstone of its sustainability

- Supporting family development and recognizing faith-based activities which are clear to the people and crucial to humanity

- Popularizing and utilizing the COWAN Tripod Empowerment Approach (i.e., health, economics and democracy) as keys to unlock the gates of self actualization through self employment and sustainable livelihoods in an integrated manner

To achieve the above stated objectives, COWAN embarked on a leaning scheme known as African Traditional Responses Banking (ATRB). This scheme incorporates the communal features of African culture known as Esusu in Nigeria, Susu in Ghana and Torteen in Cameroon. The system incorporated the social force of the society to ensure members' compliance to loan repayment. The ownership of the ATRB lies with the borrowers. This ensures quick disbursement of loans and also developed clear savings strategies as a means of repayment of loans and wealth creation.

The ATRB operates as follows:

Loans to the poorest of the poor: The target is poor women who don't have two dollars of their own to start any meaningful business. These are women who normally engage in menial jobs. This is a level ' 1 ' type of loan where beneficiaries are given small loans which spans four months. The beneficiaries are qualified for double the first loan as second loan if there is a proof consistent daily savings over a specified period of time. The loan process can be repeated over a period of one year when each beneficiary is expected to have built up a virile business with a substantial capital base.

Primary group loan: This is the level 2 loan normally given after a person has scaled the probationary level i.e., level 1 loan. Under this, women are grouped into 510 women with common business interest as cassava farming or processing. The amount of loan given to them is the total of what is due to each member of the group. There is common responsibility for the loan and the loan cycle ranges between 6 months and one year.

Community enterprise development: This is referred to as the 3rd level loan. Beneficiaries who succeed in the 2nd level are qualified for this loan, while is given to a minimum of 5 groups who must have similar business interests. In addition to the loan, grants are always given to execute a relevant community project e.g. digging of borehole, building of health centre. The loan cycle spans for one and a half year.

The banking hall: All COWAN groups have access to the banking halls where deposits are made in cash and kind e.g. farm products. The farms product deposited are sold and after three months a quarter of the profit is paid as dividends to depositors in cash in addition to the cost of production.

\section{MATERIALS AND METHODS}

The study area: The study was conducted in OndoState. The State was created on April 1st, 1976, Ondo State is bordered in the North by Ekiti and Kogi States, West by Osun State, South by Ogun State and East by Edo States. There are eighteen local government areas. The major economic activities include farming, trading and handicraft. The major crops are yam, cassava, rice, sweet potato, plantain, cocoa, palm oil, timber and kolanut among others. The State is also blessed with natural resources such as bitumen and gold. The people of the State are mostly Yorubas with different local dialects.

Nature and sources of data: The data for the study were sourced from primary and secondary sources. The secondary sources include learned journals, relevant text books, Central Bank bulletin and COWAN Publication. Primary data were collected through wellstructured questionnaire administered in 100 respondents. Data collected included age measured in years, education measured by years spent in the school and income measured in naira. Information was also collected in respondents marital status, occupational 
status, type of houses, access to basic infrastructures and the family size.

Sampling method and sample size: The study employed multi-staged sampling method. First, two local governments were randomly selected from the 18 local government areas in the State and Secondary two towns were randomly selected from each local government areas. Hence Akoko South West and Akoko North East were selected while Oka and Akungba (Akoko South West) and Ikare and Ugbe (Akoko North East) were the towns selected. The respondents comprise mainly of hairdressers, farmers, traders and teachers.

Method of data analysis: The study made use of both the descriptive and quantitative methods of analysis. Descriptive analysis such as frequency distribution, mode, means, were used to analyze the socio-economic characteristics of respondents. Multiple simple regression was used to analysis the factors affecting income of women in the study area. The significance of the variables was tested by student t-ratio, Dw statistics, F-Statistics and $\mathrm{R}^{2}$ model specification.

The following model was specified for the study.

$$
\mathrm{Y}=\mathrm{b}_{0}+\mathrm{b}_{1} \mathrm{x}_{1}+\mathrm{b}_{2} \mathrm{x}_{2}+\mathrm{b}_{3} \mathrm{x}_{3}+\mathrm{b}_{4} \mathrm{x}_{4}+\mathrm{U}
$$

Where:

$$
\begin{array}{ll}
\mathrm{Y} & =\text { Income } \\
\mathrm{x}_{1} & =\text { Age }(\text { years }) \\
\mathrm{X}_{2} & =\text { Family size } \\
\mathrm{X}_{3} & =\text { Loans } \\
\mathrm{x}_{4} & =\text { Monthly feeding } \\
\mathrm{U} & =\text { Error term } \\
\mathrm{b}_{0}, \mathrm{~b}_{1}, \mathrm{~b}_{2}, \mathrm{~b}_{3} \text { and } \mathrm{b}_{4}=\text { Parameters to be estimated. }
\end{array}
$$

\section{Data analysis:}

- Socio-economic characteristics of respondents

\section{Age distribution of respondents:}

Mean age: 39 years: The age distribution of respondents is represented in Table 1. The Table 1 shows that the modal age bracket was 45 years and above while the mean age is 39 years. The size of the mean age shows that most of the women are still in their active economic years which preclude the possibility of maximizing the economic opportunities provided by COWAN. The table further showed that 6 , 11,22 and $28 \%$ were in age bracket 24-28, 29-33, 34-38 and 39-44 respectively.
Table 1: Age distribution

\begin{tabular}{lll}
\hline Age bracket & Frequency & $(\%)$ \\
\hline $24-28$ & 6 & 6 \\
$29-33$ & 11 & 11 \\
$34-38$ & 22 & 22 \\
$39-44$ & 28 & 28 \\
45 and above & 33 & 33 \\
Total & 100 & 100 \\
\hline
\end{tabular}

Table 2: Educational status

\begin{tabular}{lll}
\hline Educational Status & Frequency & $(\%)$ \\
\hline No formal education & 35 & 35 \\
Primary education & 30 & 30 \\
Secondary education & 24 & 24 \\
Above secondary education & 11 & 11 \\
\hline
\end{tabular}

Table 3: Occupational distribution of respondents

\begin{tabular}{lll}
\hline Occupation & Frequency & $(\%)$ \\
\hline Civil Service & 20 & 20 \\
Farming & 33 & 33 \\
Trading & 17 & 17 \\
Total & 100 & 100 \\
\hline
\end{tabular}

Educational distribution of respondents: Table 2 shows that majority of the respondents $(35 \%)$ had no formal education; while $30 \%, 24 \%$ had primary and secondary education respectively. Study showed that $11 \%$ had more than secondary education. Thus distribution may likely have negative impact on the level of productivity as the productive sector needs skilled and trained labor force.

Occupational status of respondents: Table 3 shows that $33 \%$ of total respondents were farmers while 20,17 and $30 \%$ were civil servants, tailors and petit traders respectively. It could be deduced that only $20 \%$ were gainfully employed in government work while majority are engaged in subsistent farming. This underscores why most women are trapped in the poverty cycle as they do not permanent and regular source of income. The agricultural sector is faced with seasonal fluctuations which renders farm income insecure and irregular.

Impact of COWAN programs on rural women

Types of residence of respondents: Table 4 shows the type of residence inhabited by COAN Beneficiaries before and after contact with COWAN programs. Study revealed that $35,29,15$ and $21 \%$ lived in rented oneroom, rented room and parlor, rented flat and self built houses respectively before COWAN. It could be deduced from the table that only $21 \%$ of total respondents possessed the financial means for building personal house while $79 \%$ lived in hired apartments. However, with COWAN, there was improvement in the 


\section{J. Social Sci., 4 (4): 352-357, 2008}

Table 4: Distribution of respondents by type of residence

\begin{tabular}{lllll}
\hline & \multicolumn{2}{l}{ Before COWAN } & \multicolumn{2}{c}{ After COWAN } \\
\cline { 2 - 5 } Type of residence & Frequency & $(\%)$ & Frequency & $(\%)$ \\
\hline Rented Room & 35 & 35 & 32 & 32 \\
Rented room and parlour & 29 & 29 & 30 & 30 \\
Rented Flat & 15 & 15 & 11 & 11 \\
Self-built house & 21 & 21 & 27 & 27 \\
Total & 100 & 100 & 100 & 100 \\
\hline
\end{tabular}

Table 5: Distribution of respondents by type of electrical appliances

Electrical Appliances

\begin{tabular}{lll}
\hline Radio & 24 & 24
\end{tabular}

Television

Radio and Television

Radio, Television and Refrigerator

Radio, Television, Fan, Refrigerator aRadio and fan

Radio, Television, Refrigerator, Iron

Radio, Television, Refrigerator, Generator Total

$\begin{array}{ll}24 & 24 \\ 13 & 13 \\ 17 & 17 \\ 8 & 8 \\ 12 & 12 \\ 9 & 9 \\ 10 & 10 \\ 7 & 7 \\ 100 & 100\end{array}$

Table 6: Distribution of respondents by the loans obtained from COWAN

\begin{tabular}{lll}
\hline Amount of Loans Granted & Frequency & $(\%)$ \\
\hline$<$ N10,000 & 18 & 18 \\
N11,000-N15,000 & 20 & 20 \\
N16,000-N20,000 & 14 & 14 \\
N21,000-N25,000 & 15 & 15 \\
N26,000-N30,000 & 10 & 10 \\
N31,000-N35,000 & 12 & 12 \\
N36,000 and above & 11 & 11 \\
Total & 100 & 100 \\
\hline
\end{tabular}

financial status of respondents. The number of land lords rose to $27 \%$ while $73 \%$ still lived in rented buildings.

Type of electrical appliances: From Table 5, findings show that all the respondents owned at least a radio while $76 \%$ had access to television, 38\% had fan along with other facilities. This shows that the respondents have adequate access to information on COWAN.

Programs and so could maximize the enabling business environment provided by COWAN.

Loans Obtained from COWAN: The amount of loans received by respondents is shown in Table 6 .

One notable fact from Table 6 is that $89 \%$ of respondents received less than N50,000 as loan from the organization. This shows that COWAN only gives micro finance to the beneficiaries. Findings showed that majority of the respondents used the loans obtained for trading purposes (Table 7) while $46 \%$ used the loan for agricultural purposes, $11 \%$ to pay children school fees and $10 \%$ to procure grinding machines. Findings further showed that the mean monthly income of respondents was N27, 656.
Table 8: Descriptive Statistics

\begin{tabular}{lll}
\hline Variable & Mean & SD \\
\hline Income & $27,656.00$ & $17,042.23$ \\
Age & 35,4700 & 10,61394 \\
Family size & 4,6100 & 1.70498 \\
Loan & 58,148 & $42,438.2$ \\
Monthly feeding & $9,973.0$ & $9,263.2$ \\
\hline
\end{tabular}

Table 9: Results of the regression analysis

\begin{tabular}{lllll}
\hline Variables & Parameters & Coefficients & SE & t-statistics \\
\hline Constant & $\mathrm{B}_{0}$ & -1487.97 & 3965.94 & -0.375 \\
Age & $\mathrm{B}_{1}$ & 0.193 & 137.75 & 2.26 \\
Family size & $\beta_{2}$ & 0.025 & 823.41 & 0.30 \\
Loan & $\beta_{3}$ & 0.571 & 0.03 & 7.68 \\
Monthly feeding & $\mathrm{B}_{4}$ & 0.201 & 0.132 & 2.80 \\
\hline
\end{tabular}

Table 10: Return to Scale Analysis

\begin{tabular}{ll}
\hline Variable & Elasticity \\
\hline Age & 0.193 \\
Family size & 0.025 \\
Loan & 0.571 \\
Monthly feeding & 0.201 \\
RTS & 0.99 \\
\hline
\end{tabular}

- Multiple regression analysis

The results of the multiple regression is represented in Table 8 and 9.

$$
\mathrm{R}^{2}=0.60, \mathrm{~F}-\text { Statistics }=36.29, \mathrm{DW}=1.827
$$

The regression results showed a positive relationship all the explanatory variables. The $\mathrm{R}^{2}$ of 0.60 shows that $60 \%$ of total variation in total income is explained by variation in the explanatory variable. Among other things, the t-statistics showed that loans from COWAN is the most significant determinant of income of the respondents in the study area. Hence an increase in loans granted to beneficiaries will increase their income, all things being equal.

The elasticity of coefficient show that loans has a positive effect on income. An increase in loans will lead to an increase in income. The RTS of 0.99 shows that the microfinance of COWAN is quite efficient as to poverty alleviation in the study area. This can be found in Table 10.

\section{CONCLUSION}

The study examined the economic implication of COWAN's alleviation programs on rural women in Ondo State with special reference to Akoko South West and Akoko North East Local Government areas. A multi-stage sampling technique are used to select 100 respondents from the study area. Primary data were 
collected with the aid of well structured questionnaire while secondary data were collected from relevant text books, journals and COWAN publications. Data collected were analyzed through descriptive statistics and simple regression analysis. Results showed that COWAN gave small scale loan facilities which were mostly used for petit trading. Findings also showed a mean income of about $\mathrm{N} 28,000$ which is equivalent to level 6. Among other things, there was improvement in the level of asset acquisition such as personal buildings and purchase of household facilities such as radio, television, refrigerator and fan among others. Nevertheless, the level of poverty was still very high as majority are still involved in subsistence farming which is characterized by irregular income.

\section{REFERENCES}

1. Jhingan, M.L., 2003. Economic Development and Planning. 33rd Edn., Cambridge University Press, Cambridge.

2. Bullion, A., 2003. Globalization, South Asian agriculture and the WTO. South Asia Eco. J., 4: 1-18. http://direct.bl.uk/bld/PlaceOrder.do?UIN=134549 449\&ETOC $=$ RN\& from=searchengine

3. Ogunleye, B., 2004. Defining Poverty within the Nigerian context. NAPEP, 2.

4. Oladunni, E.B., 1990. The Dimension of poverty in Nigeria. Bullion, 3.

5. Afolami, C.A., 2004. Determining the Nigeria poor against the background of local situation and circumstances. NAPEP, 2.

6. Fasoranti, O.O., 2007. An exploitation of the contributions of national accelerated poverty eradication programme in Ekiti State, Nigeria. Soc. Sci., 2: 346-350.

7. Chaudhri, D.P., 1977. Education, Innovation and Agricultural Development. 2nd Edn., Vikas Pub., New Delhi.
8. Chambers, R., 1988. Rural Development: Putting the Last First. 3rd Edn., Longman Scientific and Technical, New York.

9. Akinde, C.O., 1985. A political economy of rural development: A basic need approach. Proceeding of the Local Government Administration Workshop, Ondo State University, Ado Ekiti.

10. Obadan, M., 1997. Analytical framework for poverty reduction. Proceeding of the Annual Conference of the National Economic Society, Poverty Alleviation Srategy: Implication for Development, Sep. 15-15, Kaduna, Nigeria, pp: 150-157.

11. Okunmadewa, F., 1997. Poverty alleviation efforts of United Nations agencies in Nigeria. Partnership for Develop., 1.

12. Olowononi, G., 1997. Towards a sustainable programme for poverty alleviation in Nigeria. Proceeding of the Annual Conference of NES, Poverty Alleviation Strategy: Implication for Development, (ACPASID'97), Kaduna, Nigeria, pp: 206-210.

13. Evbuomwan, G., 1997. Poverty alleviation through agricultural project. A review of the concept of the World Bank Assisted ADPs in Nigeria. CBN Bull., 21: 11-15.

14. Cowan, 2002. Monthly Bull., 5: 5-8. 